\title{
QUALIDADE QUÍMICA E FÍSICA DO SOLO SOB VEGETAÇÃO ARBÓREA NATIVA E PASTAGENS NO PANTANAL SUL-MATO-GROSSENSE ${ }^{(1)}$
}

\author{
Evaldo Luis Cardoso(2), Marx Leandro Naves Silva ${ }^{(3)}$, Nilton Curi ${ }^{(3)}$, Mozart \\ Martins Ferreira $^{(3)}$ \& Diego Antônio França de Freitas ${ }^{(4)}$
}

\begin{abstract}
RESUMO
A busca por aumento de produtividade da pecuária pantaneira tem motivado o desmatamento de áreas florestadas para a implantação de pastagem cultivada, gerando preocupação quanto à sustentabilidade dos recursos naturais. Para estudar alguns aspectos de uso do solo no Pantanal Sul-Mato-Grossense, este trabalho teve por objetivo avaliar as alterações nos atributos químicos e físicos do solo em razão da conversão da vegetação arbórea nativa em pastagem cultivada, bem como da submissão da pastagem nativa ao sistema de pastejo contínuo. Os ambientes de estudo consistiram de três remanescentes de vegetação arbórea nativa, representadas por uma floresta semidecídua (FN) e dois cerradões (CE1 e CE2), três pastagens de Brachiaria decumbens com 27, 26 e 11 anos de formação, implantadas em substituição a FN, CE1 e CE2, respectivamente, e uma pastagem nativa caracterizada pela predominância de Mesosetum chaseae e Axonopus purpusii, submetida a três diferentes sistemas de pastejo (contínuo e sem pastejo por 3 e 19 anos). Amostras de solo, deformadas e indeformadas, foram coletadas em cada ambiente de estudo, nas profundidades de 0-10 e 10-20 cm, com três repetições. A substituição da vegetação arbórea nativa por pastagem cultivada e o sistema de pastejo contínuo da pastagem nativa determinaram redução da qualidade química do solo, evidenciada principalmente por perdas de matéria orgânica do solo, notadamente na profundidade de 0-10 cm. Embora a qualidade física do solo também tenha apresentado tendência à redução nas pastagens cultivada e nativa sob pastejo contínuo, a densidade do solo, porosidade total, macroporosidade, microporosidade, condutividade hidráulica do solo saturado e
\end{abstract}

(1) Parte da Tese de Doutorado do primeiro autor apresentada ao Curso de Pós-Graduação em Ciência do Solo da Universidade Federal de Lavras - UFLA. Executado com recursos do CNPq. Recebido para publicação em abril de 2010 e aprovado em dezembro de 2010.

(2) Pesquisador da Embrapa Pantanal. Rua 21 de setembro, 1880, Caixa Postal 109, CEP 79320-900 Corumbá (MS). E-mail: evaldo@cpap.embrapa.br

(3) Professor do Departamento de Ciência do Solo, Universidade Federal de Lavras - DCS/UFLA. Caixa Postal 3037, CEP 37200 000 Lavras (MG). E-mails: marx@dcs.ufla.br; niltcuri@dcs.ufla.br, mozartmf@dcs.ufla.br

(4) Doutorando do Programa de Pós-Graduação em Ciência do Solo, UFLA. E-mail: diego ufla@yahoo.com.br 
resistência do solo à penetração não atingiram valores considerados limitantes ao desenvolvimento do sistema radicular.

Termos de indexação: vegetação nativa, desmatamento, degradação do solo, uso do solo.

\title{
SUMMARY: SOIL CHEMICAL AND PHYSICAL QUALITY UNDER NATURAL TREE VEGETATION AND PASTURE IN THE PANTANAL WETLANDS, SOUTH OF MATO GROSSO, BRAZIL
}

\begin{abstract}
The search for improved productivity of livestock has stimulated deforestation of forested areas in the Pantanal for pasture planting, raising concerns about the sustainability of the natural resources. To study some aspects of land use in the Pantanal of Mato Grosso, Brazil, this study aimed to evaluate the changes in chemical and physical soil properties due to the conversion of native tree vegetation in pasture, and the exposure of native pasture to a continuous grazing system. The environments of the study consisted of three remnants of native vegetation, represented by a semi-deciduous forest (NF) and two Cerrado (CE1 and CE2) areas, three 27, 26 and 11-year-old Brachiaria decumbens pastures, planted to replace FN, CE1 and CE2, respectively, and a native pasture with predominance of Mesosetum chaseae and Axonopus purpusii, under three different grazing systems (continuous and ungrazed for 3 and 19 years). Disturbed and undisturbed soil samples were collected from each study environment, in the layers $0-10$ and 10-20 $\mathrm{cm}$, with three replications. The replacement of native tree vegetation by pasture and by continuous grazing of native pasture resulted in a reduction of the soil chemical quality, evidenced primarily by a loss of soil organic matter, particularly in the layer $0-10 \mathrm{~cm}$. Although the soil physical quality also tends to decrease under cultivated and native pasture under continuous grazing, the values of bulk density, total porosity, macroporosity, microporosity, hydraulic conductivity of saturated soil and soil penetration resistance did not reach levels considered critical for root development.
\end{abstract}

Index terms: native vegetation, deforestation, soil degradation, land use.

\section{INTRODUÇÃO}

A preocupação com a conservação dos recursos naturais tem sido crescente nas últimas décadas, especialmente em relação a biomas como o do Pantanal Mato-Grossense, reconhecido como Reserva da Biosfera e Patrimônio da Humanidade. Nessa imensa planície inundável, a pecuária de corte constitui-se na principal atividade econômica, porém, assim como nas demais regiões tropicais que criam bovinos extensivamente em pastagem nativa, apresenta baixos índices zootécnicos (Santos et al., 2002). Como alternativa para aumentar a oferta de forragens e elevar a produtividade da pecuária pantaneira, têm sido promovidos desmatamentos para a implantação de pastagem cultivada, gerando preocupação quanto à sustentabilidade desses agroecossistemas no Pantanal, uma vez que essas pastagens são implantadas em solos de textura arenosa, com baixa fertilidade natural e sem jamais realizar a correção de acidez e mesmo adubação.

Os ecossistemas naturais apresentam integração harmoniosa entre a cobertura vegetal e os atributos do solo, decorrente de processos essenciais de ciclagem de nutrientes e acumulação e decomposição da matéria orgânica. Entretanto, a ação antrópica promove alterações nesses atributos e, na maioria das vezes, causa impacto ambiental negativo (Silva et al., 2007). De acordo com Bayer \& Mielniczuk (2008), sob vegetação natural a matéria orgânica do solo se encontra estável e, quando submetida ao uso agrícola, pode ocorrer redução acentuada no seu conteúdo, principalmente quando utilizados métodos de preparo com intenso revolvimento do solo e sistemas de cultura com baixa adição de resíduos. Nessa situação, pode ser estabelecido um processo de degradação das condições químicas, físicas e biológicas do solo, além de perda da produtividade das culturas.

A conversão de sistemas naturais em agrícolas pode resultar em compactação do solo, devido ao pisoteio animal, tráfego de máquinas e implementos agrícolas, cultivo intensivo e sistema de manejo inadequado (Hamza \& Anderson, 2005). O grau de compactação provocado pelo pisoteio animal pode ser influenciado pela textura, pelo sistema de pastejo, pela altura de manejo da pastagem, pela quantidade de resíduo vegetal na superfície e pela umidade do solo (Lanzanova et al., 2008). 
As inter-relações das propriedades do solo controlam os processos e os aspectos relacionados a sua variação espacial e temporal, de tal forma que qualquer alteração pode afetar diretamente a sua estrutura e a atividade biológica e, consequentemente, a sua qualidade (Carneiro et al., 2009). Avaliações de alterações nas propriedades do solo, decorrentes de impactos da intervenção antrópica em ecossistemas naturais, podem constituir importante instrumento para auxiliar no monitoramento da conservação ambiental, pois permitem caracterizar a situação atual, alertar para situações de risco e, por vezes, prever situações futuras, especialmente quando adotada como referência a vegetação nativa original. Apesar do expressivo volume de trabalhos sobre o efeito de diferentes sistemas de uso e manejo do solo, especialmente no Cerrado, ainda são escassos resultados em outros importantes biomas brasileiros, sobretudo daqueles que elucidam alterações provocadas pela substituição da floresta nativa por pastagem cultivada.

Especificamente para o Pantanal, cujas florestas nativas estão estabelecidas em solos de baixa fertilidade natural e têm sua manutenção fortemente associada ao equilíbrio entre a cobertura vegetal e os processos biogeoquímicos do solo (Cardoso et al., 2009), a avaliação das propriedades do solo que estimam a sua qualidade assume importante papel no monitoramento de sua conservação, sob pena de a degradação do solo comprometer irreversivelmente a sustentabilidade dos agroecossistemas. Nesse sentido, o objetivo deste trabalho foi avaliar as alterações nos atributos químicos e físicos do solo em razão da conversão da vegetação arbórea nativa em pastagem cultivada, bem como da submissão da pastagem nativa ao sistema de pastejo contínuo no Pantanal Sul-Mato-Grossense.

\section{MATERIAL E MÉTODOS}

O trabalho foi conduzido em dois estabelecimentos rurais localizados na sub-região da Nhecolândia, Pantanal Sul-Mato-Grossense, cujos ambientes avaliados consistiram de três remanescentes de vegetação arbórea nativa; três pastagens cultivadas implantadas em substituição à vegetação arbórea; $\mathrm{e}$ uma pastagem nativa caracterizada pela predominância de Mesosetum chaseae e Axonopus purpusii, submetida ao sistema de pastejo contínuo e ausência de pastejo.

Os ambientes de estudo apresentam a seguinte caracterização e localização: FN - remanescente de floresta semidecídua ( $18^{\circ} 34$ ' 57 " S e $55^{\circ} 50$ ' 52 ” W), caracterizada pela ocorrência de 24 diferentes espécies (altura média de 12,4 m e diâmetro médio de 27,0 cm), em que Attalea phalerata, Rhamnidium elaeocarpum e Astronium fraxinifoliums destacam-se como mais abundantes; PC27 - pastagem cultivada de Brachiaria decumbens com 27 anos de formação, implantada em substituição a FN e contígua ao remanescente; CE1 - remanescente de cerradão $\left(18^{\circ} 33^{\prime} 11\right.$ " S e $55^{\circ} 48^{\prime} 41$ ” W), caracterizado pela ocorrência de 30 diferentes espécies (altura média de 11,7 m e diâmetro médio de 15,8 cm), em que Qualea grandiflora, Caryocar brasiliense e Lafoensia pacar destacam-se como mais abundantes; PC26 - pastagem cultivada de Brachiaria decumbens com 26 anos de formação, implantada em substituição ao CE1 e contígua ao remanescente; CE2 - remanescente de cerradão $\left(18^{\circ} 59^{\prime} 57^{\prime \prime}\right.$ S e $56^{\circ} 38^{\prime} 10$ ” W), caracterizado pela ocorrência de 43 diferentes espécies (altura média de 7,5 m e diâmetro médio de $12,4 \mathrm{~cm}$ ), em que Alibertia sessili, Protium heptaphyllum e Zanthoxylum rigidum destacam-se como mais abundantes; PC11 pastagem cultivada de Brachiaria decumbens com 11 anos de formação, implantada em substituição ao $\mathrm{CE} 2$ e contígua ao remanescente; $\mathrm{PNpc}$ - pastagem nativa submetida ao sistema de pastejo contínuo $\left(18^{\circ} 59^{\prime} 25^{\prime}\right.$ " S e $\left.56^{\circ} 38^{\prime} 43^{\prime \prime} \mathrm{W}\right)$; PNv3 - pastagem nativa sem pastejo por 3 anos $\left(18^{\circ} 59^{\prime} 57^{\prime} \mathrm{S}\right.$ e $56^{\circ} 38^{\prime} 01$ ” W), três parcelas de $10 \times 10 \mathrm{~m}$ cercadas com fios de arame e alocadas aleatoriamente na PNpc; e PNv19 - pastagem nativa sem pastejo por 19 anos (18 ${ }^{\circ} 58^{\prime} 42^{\prime}$ 'S e $56^{\circ} 37^{\prime} 00$ ” W), em área de Reserva Particular do Patrimônio Natural (RPPN).

A descrição da distribuição e abundância das espécies arbóreas nas áreas florestadas encontra-se em Salis (2004). O solo dos ambientes sem intervenção antrópica (FN, CE1, CE2 e PNv19) foi classificado conforme os procedimentos estabelecidos por Lemos \& Santos (1996) e Embrapa (2006), cujos resultados são apresentados no quadro 1 . As pastagens cultivadas e nativas são manejadas sem jamais incluir correção do solo ou qualquer tipo de adubação, sendo as cultivadas implantadas após a derrubada e queima da floresta nativa e, diferentemente das nativas, mantidas por curto período durante o ano ausentes de pastejo. A lotação animal nas pastagens pode variar de 0,8 a 1,0 UA ha-1 na pastagem cultivada e de 0,2 a $0,5 \mathrm{UA} \mathrm{ha}^{-1}$ na pastagem nativa.

Amostras deformadas e indeformadas de solo foram coletadas aleatoriamente em cada ambiente de estudo, nas camadas de 0-10 e 10-20 cm, com três repetições. As amostras deformadas foram secas ao ar, passadas em peneiras (malha de $2 \mathrm{~mm}$ ) e submetidas às seguintes análises, conforme método descrito por Embrapa (1997): $\mathrm{pH}$ em água (1:2,5); $\mathrm{Ca}^{2+}, \mathrm{Mg}^{2+} \mathrm{e}$ $\mathrm{Al}^{3+}$ trocáveis, extraídos com solução de $\mathrm{KCl} 1 \mathrm{~mol} \mathrm{~L}^{-1}$ e determinados por espectrofotometria de absorção atômica; $\mathrm{P}$ disponível e $\mathrm{K}$ trocável, extraídos com solução ácida (Mehlich-1), sendo o $\mathrm{P}$ quantificado por colorimetria e K por fotometria de chama; e o conteúdo de matéria orgânica do solo (MOS), obtido pelo teor de C orgânico determinado por oxidação via úmida. Com os resultados das análises químicas, foram calculados os valores de soma de bases trocáveis (SB), capacidade de troca catiônica efetiva (t) e capacidade de troca catiônica a pH 7,0 (T). Nas amostras indeformadas foram determinadas, em laboratório, conforme descrito por Embrapa (1997): densidade do solo (Blake \& 
Quadro 1. Caracterização morfológica, física e química do solo dos ambientes FN, CE1 e CE2 estudados no Pantanal Sul-Mato-Grossense

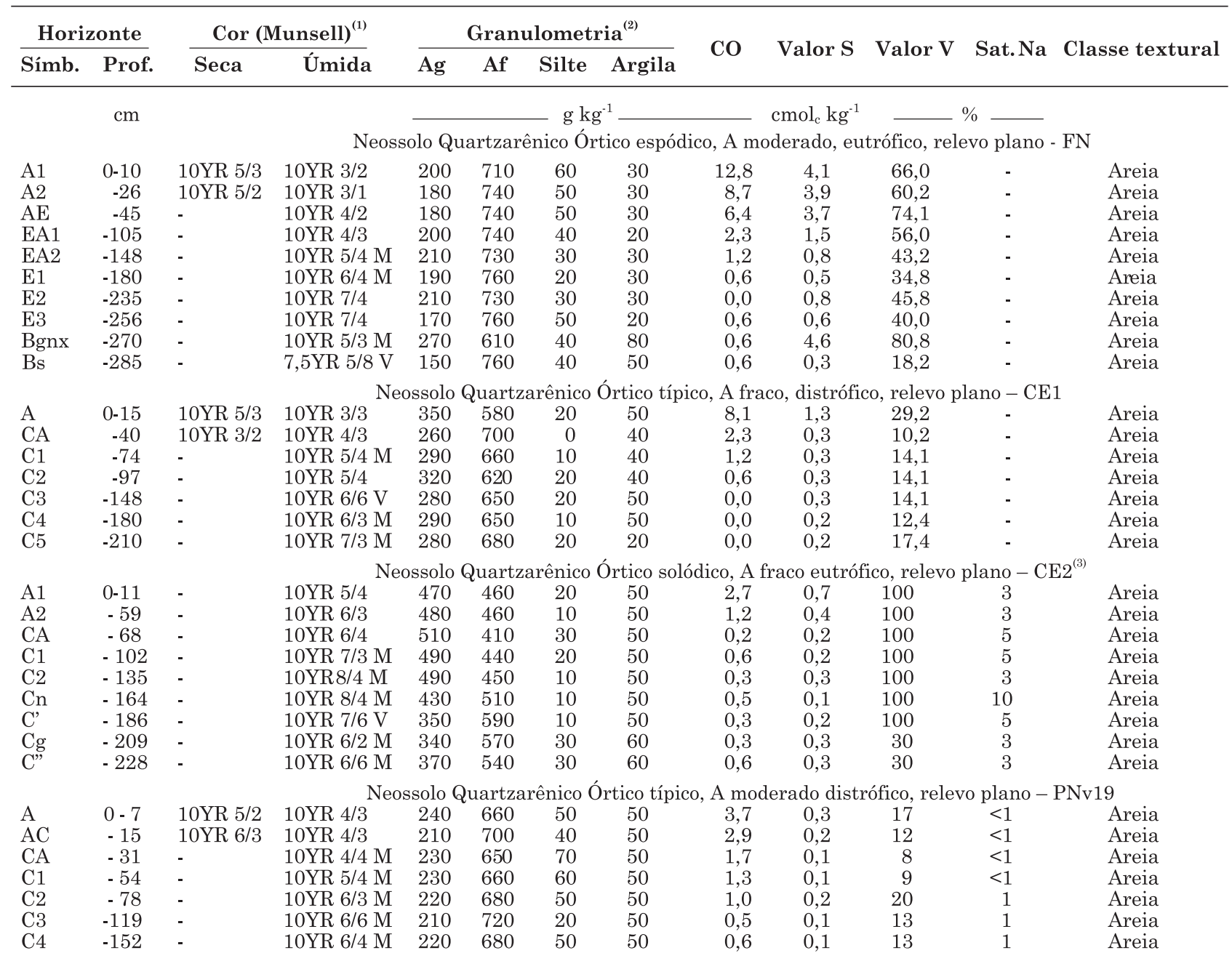

(1) Cor dominante (M: com mosqueamento abundante; V: coloração variegada). ${ }^{(2)}$ Ag: areia grossa; Af; areia fina; CO: carbono orgânico; Valor S: soma de bases trocáveis; Valor T: saturação por bases; Sat. Na: saturação por Na+; FN: floresta semidecídua; CE1 e CE2: cerradão; PNv19: pastagem nativa sem pastejo por 19 anos (RPPN). ${ }^{(3)}$ Perfil descrito por Santos et al. (1997).

Hartge, 1986); porosidade total, macroporosidade e microporosidade em mesa de tensão; e condutividade hidráulica do solo saturado. No campo, a resistência do solo à penetração foi avaliada utilizando-se penetrômetro de impacto (modelo IAA/PlanalsucarStolf), cujos resultados foram calculados de acordo com Stolf (1991), a partir da fórmula: RP $\left(\mathrm{kgf} \mathrm{cm}^{-2}\right)=5,6$ $+6,89 \mathrm{~N}$ (impacto $\mathrm{dm}^{-1}$ ). Para a conversão de kgf $\mathrm{cm}^{-2}$ para MPa, multiplicou-se o resultado obtido na equação pela constante 0,0981. A umidade do solo no momento do teste de resistência à penetração foi determinada pelo método gravimétrico (Embrapa, 1997).

Os resultados foram submetidos à análise de variância, adotando-se o delineamento experimental inteiramente casualizado, com três repetições, conforme os procedimentos do SISVAR (Ferreira, 2000). As comparações para verificação do efeito da conversão da vegetação arbórea nativa em pastagem cultivada, bem como da submissão da pastagem nativa ao sistema de pastejo contínuo, foram realizadas por meio de contrastes ortogonais, a partir do desdobramento dos oito graus de liberdade dos ambientes de estudo. A significância dos contrastes de interesse, com um grau de liberdade, foi testada pelo teste $\mathrm{F}$ a pelo menos $5 \%$, levando-se em conta o quadrado médio do resíduo obtido pela análise de variância.

\section{RESULTADOS E DISCUSSÃO}

As pastagens promoveram alterações significativas nos atributos químicos do solo, notadamente na camada de 0-10 cm, o que é evidenciado pela redução da fertilidade do solo nas áreas de pastagens cultivadas PC27, PC26 e PC11, implantadas em substituição às respectivas vegetações nativas $\mathrm{FN}$, 
CE1 e CE2 (Quadro 2). O mesmo processo ocorre na pastagem nativa submetida ao sistema de pastejo contínuo (PNpc), quando comparada com a pastagem nativa sem pastejo por 19 anos (PNv19), porém sem diferir da pastagem nativa sem pastejo por três anos (PNv3). A acidez ativa do solo não foi alterada nas pastagens cultivada e nativa sob pastejo contínuo, cujos valores de $\mathrm{pH}$ variaram de 4,8 a 6,4 e de 4,9 a 6,3 nas camadas de $0-10$ e $10-20 \mathrm{~cm}$, respectivamente, podendo ser classificada como acidez fraca a elevada (Alvarez V. et al., 1999). Por outro lado, a acidez potencial $(\mathrm{H}+\mathrm{Al})$ foi significativamente mais alta nos ambientes sem intervenção antrópica e de esperado equilíbrio (FN, CE1, CE2 e PNv19), sendo dominada pela presença de íons $\mathrm{H}^{+}$e baixos teores de $\mathrm{Al}^{3+}$. Esses resultados comprovam que a matéria orgânica do solo pode se constituir em uma importante fonte de acidez potencial nos solos tropicais (Canellas et al., 2003), principalmente nos ambientes caracterizados por formação de serapilheira acumulada, como observado nas áreas florestadas.

Em relação ao $\mathrm{P}$ disponível, a conversão da vegetação arbórea em pastagem cultivada e o sistema de pastejo contínuo da pastagem nativa não promoveram alterações significativas nos teores, nas duas camadas amostradas. De acordo com GamaRodrigues et al. (2008), a não variação nos teores de P disponível em solos sob diferentes coberturas vegetais estaria associada à grande estabilidade do $\mathrm{P}$ em solos muito intemperizados, onde forma complexos de esfera-interna na superfície dos óxidos de ferro e alumínio (Meurer, 2006). Por outro lado, os teores de $\mathrm{K}^{+}, \mathrm{Ca}^{2+}$ e $\mathrm{Mg}^{2+}$ trocáveis e de matéria orgânica do solo (MOS) e os valores de soma de bases trocáveis (SB), capacidade de troca catiônica a pH 7,0 (T) e

Quadro 2. Atributos químicos do solo em diferentes ambientes do Pantanal Sul-Mato-Grossense e significância dos contrastes de interesse

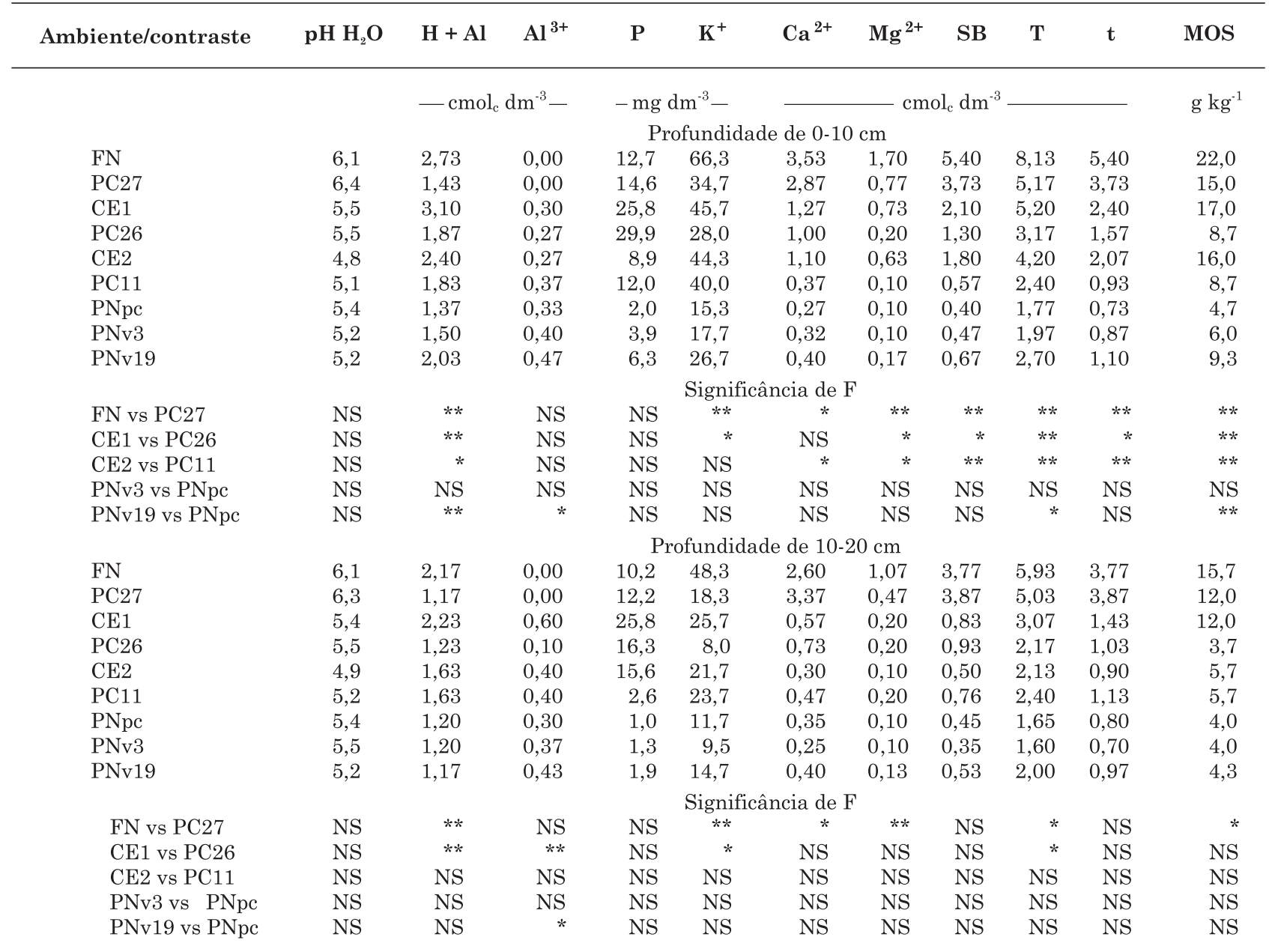

FN: mata semidecídua; CE1 e CE2: cerradão; PC27, PC26, PC11: respectivamente, pastagem cultivada com 27, 26 e 11 anos de formação; PNpc, PNv3, PNv19: respectivamente, pastagem nativa com sistema de pastejo contínuo e sem pastejo por 3 e 19 anos (RPPN). SB: soma de bases trocáveis; T: capacidade de troca de cátions a $\mathrm{pH}$ 7,0: t: capacidade de troca efetiva; MOS: matéria orgânica do solo. * $\mathrm{e} * *$ respectivamente, significativo a 5 e $1 \%$; NS Não significativo. 
capacidade de troca catiônica efetiva (t) foram significativamente reduzidos pela conversão da vegetação arbórea em pastagem cultivada, notadamente na camada de $0-10 \mathrm{~cm}$. Por sua vez, $\mathrm{o}$ sistema de pastejo contínuo da pastagem nativa determinou redução apenas na T e no teor de MOS, quando comparado com a pastagem sem pastejo por 19 anos (PNv19), não diferindo da pastagem sem pastejo por três anos (PNv3) (Quadro 2). Esses resultados podem ser atribuídos à menor reciclagem de nutrientes nas pastagens, condicionada pelo menor aporte de substrato orgânico ao solo, cujo processo de decomposição e mineralização provavelmente constitui a principal fonte de nutrientes para as plantas em ecossistemas de baixa fertilidade natural e não fertilizados (Moreira \& Malavolta, 2004), como é o caso dos agroecossistemas do Pantanal.

Nota-se ainda que os teores de $\mathrm{Ca}^{2+}$ e $\mathrm{Mg}^{2+}$ trocáveis e os valores de SB, T e t apresentaram tendência de redução mais acentuada nas pastagens implantadas em substituição ao CE1 e CE2 $\left(\mathrm{Ca}^{2+}=\right.$ 21 e $66 \% ; \mathrm{Mg}^{2+}=73$ e $84 \% ; \mathrm{SB}=38$ e $68 \% ; \mathrm{T}=39$ e $43 \%$; $=35$ e $55 \%$, respectivamente, nas pastagens PC26 e PC11), indicando que a qualidade química do solo é mais suscetível à degradação quando a implantação de pastagem cultivada ocorre em substituição à vegetação nativa caracterizada por árvores de menor porte e de fertilidade natural do solo mais baixa (CE2), independentemente do tempo de remoção dessa vegetação. A degradação química do solo sob pastagem nativa, evidenciada apenas por redução da T e da MOS, sugere considerável resiliência desses campos nativos, provavelmente condicionada pelo ciclo anual de cheia, quando há aporte de matéria orgânica e de nutrientes de outros locais, além de criar, temporariamente, nas áreas de alagamento, um ambiente onde predominam reações de redução, o qual ocorre menor taxa de oxidação da MOS (Meurer, 2006). Essa assertiva é corroborada pelo uso dessas pastagens sob pastejo contínuo há mais de 200 anos, sem jamais incluir qualquer tipo de adubação e, em geral, sem apresentar severa degradação aparente.

A redução nos teores de MOS corresponderam na camada de $0-10 \mathrm{~cm}$ a 32,49 e $46 \%$ nas pastagens $\mathrm{PC} 27, \mathrm{PC} 26$ e $\mathrm{PC} 11$, respectivamente, em relação à vegetação nativa, e a 49 \% na $\mathrm{PNpc}$ em relação a PNv19 (Quadro 2). De acordo com Costa et al. (2009), os teores de $\mathrm{C}$ encontrados em solos sob vegetação nativa e pastagens implantadas em sua substituição são, muitas vezes, são contraditórios. Alguns autores relatam teores iguais ou superiores nos solos sob pastagem em relação aos ambientes de mata (Araújo et al., 2007; Rangel \& Silva, 2007; Carneiro et al., 2009; Silva Júnior et al., 2009), sendo atribuídos, em grande parte, ao maior aporte de material orgânico proporcionado pelo sistema radicular das gramíneas, que é desenvolvido e bem distribuído, enquanto outros apontam teores mais altos nos solos sob vegetação de mata nativa (Oliveira et al., 2008; Portugal et al., 2008), geralmente atribuídos ao maior aporte global de material orgânico na mata em relação às pastagens, estando estas geralmente degradadas.

Assim como no presente trabalho, Fernandes et al. (1999) relataram que os teores de C em pastagem com 10 anos de formação no Pantanal foram iguais aos do cerrado nativo nos primeiros $10 \mathrm{~cm}$ e menores a partir dessa profundidade. Na pastagem com 20 anos de formação, por sua vez, foram $25 \%$ e $32 \%$ menores nas camadas de $0-10$ e $10-20 \mathrm{~cm}$ de profundidade, respectivamente. Os maiores teores de MOS observados nos ambientes sem intervenção antrópica avaliados no presente estudo provavelmente estão associados ao maior aporte, de forma contínua e com conteúdo variado, de material orgânico com diferentes graus de suscetibilidade à decomposição, provenientes de uma vegetação com maior diversidade de espécies. Ressalta-se ainda que os campos naturais do Pantanal, em geral, são submetidos à permanente desfolha, imposta pela pressão de pastejo, caracterizando esses ambientes como sistemas marcados apenas pela extração de biomassa e, basicamente, sem nenhuma reposição (Cardoso et al., 2009), além dos excrementos animais depositados em locais pontuais.

Segundo Bayer \& Mielniczuk (2008), a matéria orgânica é um componente fundamental na capacidade produtiva dos solos, por causa dos seus efeitos sobre a disponibilidade de nutrientes, a complexação de elementos tóxicos e micronutrientes, a agregação, a infiltração e retenção de água, a aeração e a atividade e biomassa microbiana. Portanto, em função da textura arenosa e da baixa disponibilidade de nutrientes minerais dos solos predominantes nos diferentes ambientes do Pantanal, a MOS assume papel relevante na reciclagem de nutrientes, e atividades produtivas que promovam a redução no seu teor no solo podem contribuir para a degradação da qualidade deste, interferir no equilíbrio do sistema e, consequentemente, comprometer a sustentabilidade dos agroecossistemas.

Em relação aos atributos físicos do solo, foi constatado aumento na densidade do solo e na resistência deste à penetração e redução na porosidade total, macroporosidade e condutividade hidráulica do solo saturado em todas as áreas com pastagens, enquanto a microporosidade foi alterada significativamente na PC26 e PC11 (Quadro 3). Esses resultados provavelmente estão associados à maior pressão mecânica sobre o solo, exercida pelo pisoteio dos animais, e à redução no teor de MOS nas pastagens. Resultados semelhantes determinados em vegetação nativa e em pastagens têm sido amplamente relatados na literatura (Araújo et al., 2007; Lanzanova et al., 2008; Portugal et al., 2008; Aratani et al., 2009; Carneiro et al., 2009). Mesmo havendo aumento significativo da densidade do solo nas pastagens cultivada e nativa sob pastejo contínuo, constata-se que os valores observados encontram-se abaixo do 
Quadro 3. Atributos físicos do solo em diferentes ambientes do Pantanal Sul-Mato-Grossense e significância dos contrastes de interesse

\begin{tabular}{|c|c|c|c|c|c|c|c|c|c|c|}
\hline $\begin{array}{l}\text { Ambiente/ } \\
\text { contraste }\end{array}$ & Ds & $\mathbf{P t}$ & Mic & Mac & $\mathbf{K s}$ & Ds & $\mathbf{P t}$ & Mic & Mac & $\mathbf{K s}$ \\
\hline & $\mathrm{kg} \mathrm{dm}^{-3}$ & $\longrightarrow$ & $m^{3} m^{-5}$ & - & $\mathrm{mm} \mathrm{h}^{-1}$ & $\mathrm{~kg} \mathrm{dm}^{-3}$ & $\longrightarrow$ & $\mathrm{m}^{3} \mathrm{~m}^{-3}$ & - & $\mathrm{mm} \mathrm{h}^{-1}$ \\
\hline & \multicolumn{5}{|c|}{ Profundidade de $0-10 \mathrm{~cm}$} & \multicolumn{5}{|c|}{ Profundidade de $10-20 \mathrm{~cm}$} \\
\hline $\mathrm{FN}$ & 1,40 & 0,44 & 0,19 & 0,25 & 447,3 & 1,50 & 0,41 & 0,18 & 0,24 & 408,7 \\
\hline $\mathrm{PC} 27$ & 1,56 & 0,39 & 0,22 & 0,17 & 161,7 & 1,59 & 0,38 & 0,21 & 0,17 & 219,7 \\
\hline CE1 & 1,50 & 0,43 & 0,13 & 0,29 & 423,3 & 1,49 & 0,43 & 0,12 & 0,32 & 489,0 \\
\hline $\mathrm{PC} 26$ & 1,59 & 0,38 & 0,26 & 0,12 & 185,3 & 1,66 & 0,37 & 0,21 & 0,16 & 142,7 \\
\hline $\mathrm{CE} 2$ & 1,44 & 0,43 & 0,13 & 0,30 & 404,5 & 1,44 & 0,45 & 0,15 & 0,30 & 482,3 \\
\hline $\mathrm{PC} 11$ & 1,56 & 0,39 & 0,25 & 0,14 & 164,7 & 1,54 & 0,40 & 0,22 & 0,18 & 147,3 \\
\hline $\mathrm{PNpc}$ & 1,61 & 0,38 & 0,23 & 0,15 & 143,0 & 1,60 & 0,39 & 0,17 & 0,21 & 264,2 \\
\hline PNv3 & 1,57 & 0,40 & 0,22 & 0,19 & 269,0 & 1,60 & 0,39 & 0,20 & 0,19 & 302,5 \\
\hline \multirow[t]{2}{*}{ PNv19 } & 1,45 & 0,43 & 0,22 & 0,21 & 383,0 & 1,54 & 0,40 & 0,21 & 0,19 & 293,7 \\
\hline & \multicolumn{5}{|c|}{ Significância de F } & \multicolumn{5}{|c|}{ Significância de F } \\
\hline $\mathrm{FN}$ vs $\mathrm{PC} 2$ & ** & ** & NS & $* *$ & $* *$ & $* *$ & * & NS & * & * \\
\hline $\mathrm{CE} 1$ vs $\mathrm{PC} 2$ & $* *$ & $* *$ & $* *$ & $* *$ & $* *$ & $* *$ & $* *$ & $*$ & $* *$ & $* *$ \\
\hline CE2 vs PC11 & $* *$ & $* *$ & $* *$ & $* *$ & $* *$ & $* *$ & $* *$ & NS & $* *$ & $* *$ \\
\hline PNv3 vs PNpc & NS & NS & NS & NS & NS & NS & NS & NS & NS & NS \\
\hline PNv19 vs PNpc & $* *$ & $* *$ & NS & $*$ & $* *$ & NS & NS & NS & NS & NS \\
\hline
\end{tabular}

FN: mata semidecídua; CE1 e CE2: cerradão; PC27, PC26, PC11: respectivamente, pastagem cultivada com 27, 26 e 11 anos de formação; PNpc, PNv3, PNv19: respectivamente, pastagem nativa com sistema de pastejo contínuo e sem pastejo por 3 e 19 anos (RPPN). DS: densidade do solo; Pt: porosidade total; Mic: microporosidade; Mac. macroporosidade;. Ks: condutividade hidráulica do solo saturado. ${ }^{*} \mathrm{e}{ }^{* *}$ respectivamente, significativo a 5 e $1 \%$; ${ }^{\text {NS }}$ Não significativo.

limite considerado como restritivo ao desenvolvimento do sistema radicular, que, para solos arenosos, seria de 1,70-1,75 $\mathrm{kg} \mathrm{dm}^{-3}$ (Arshad et al., 1996). O maior valor de densidade observado na PNpc $\left(1,61 \mathrm{~kg} \mathrm{dm}^{-3}\right)$, apesar de suportar menor lotação animal do que a pastagem cultivada $\left(0,2\right.$ a $0,5 \mathrm{UA} \mathrm{ha}^{-1}$ na pastagem nativa e 0,8 a $1,0 \mathrm{UA} \mathrm{ha}^{-1}$ na pastagem cultivada), evidencia que a compactação do solo, nos ambientes avaliados, provavelmente está mais associada ao sistema de pastejo do que propriamente ao tipo de pastagem, se natural ou cultivada. Ressalta-se, ainda, que o período de três anos sem pastejo na pastagem nativa (PNv3) não foi suficiente para promover reestruturação do solo, uma vez que a densidade deste não diferiu significativamente daquela do pastejo contínuo (PNpc).

A resistência do solo à penetração apresentou o mesmo comportamento observado para a densidade do solo, com leve tendência à compactação nas áreas de pastagens (Figura 1), cujos valores também se encontram abaixo do limite crítico para causar prejuízos ao desenvolvimento do sistema radicular, apontado como $2 \mathrm{MPa}$ (Arshad et al., 1996). Como a resistência à penetração geralmente aumenta com a compactação (incremento da densidade) e redução do teor de água no solo (Benghough \& Mullins, 1990), a ausência de diferença significativa nos teores de água (Figura 1) sugere que os maiores valores de resistência observados nas pastagens estão associados à redução no teor de MOS e ao pisoteio animal (Fidalski et al.,
2008), notadamente na camada superficial, e aos ciclos de umedecimento e secagem do solo, que promovem o rearranjo das partículas (Oliveira et al., 1996).

A porosidade total, a macroporosidade e a condutividade hidráulica do solo apresentaram, de forma coerente, uma relação inversa à densidade do solo e à resistência à penetração, ou seja, menores valores foram encontrados nas pastagens cultivada e nativa sob pastejo contínuo (Quadro 3), evidenciando um solo mais poroso e permeável nos ambientes sem intervenção antrópica (FN, CE1, CE2 e PNv19). Apesar da redução da macroporosidade nas áreas com pastagens, as quais são mais intensamente alteradas pela pressão mecânica sobre o solo exercida pelo pisoteio animal (Bertol et al., 2000), os valores observados encontram-se acima de $0,10 \mathrm{~m}^{3} \mathrm{~m}^{-3}$, limite abaixo do qual as trocas gasosas e o crescimento das raízes da maioria das culturas podem ser prejudicados (Taylor \& Ashcroft, 1972). Ressalta-se, ainda, a expressiva redução no fluxo de água nas pastagens cultivada e nativa sob pastejo contínuo em relação ao respectivo ambiente natural, a qual correspondeu a 64 e $46 \%$ na PC27, 56 e $70 \%$ na PC26, 59 e $69 \%$ na PC11 e 63 e $10 \%$ PNpc, nas camadas de 0-10 e 10$20 \mathrm{~cm}$ de profundidade, respectivamente. A redução nos valores de condutividade hidráulica em solos cultivados em comparação com os de mata nativa reflete a redução dos poros de maior diâmetro, os quais são responsáveis pela aeração e pela drenagem da água no perfil do solo (Assis \& Lanças, 2005). 


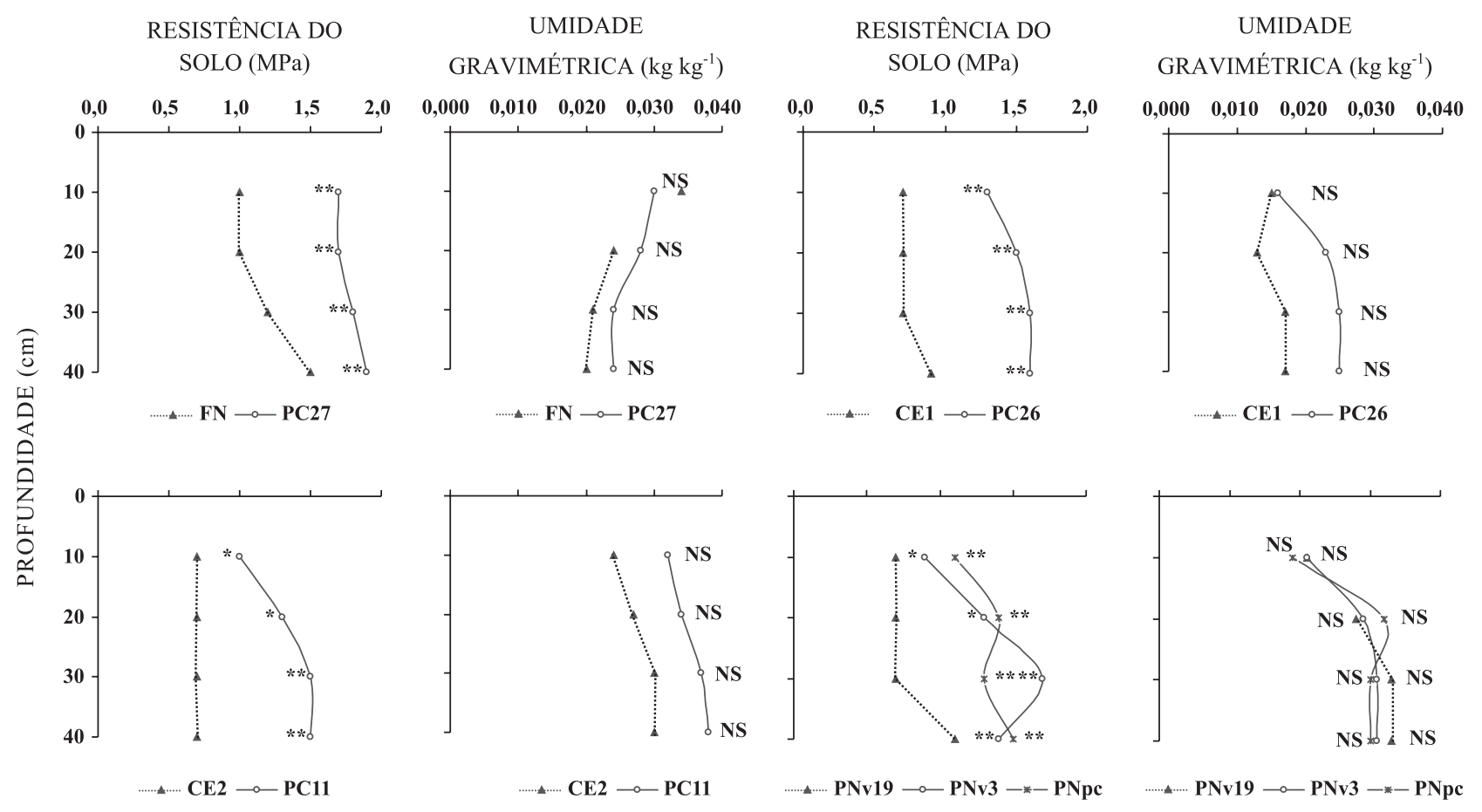

Figura 1. Resistência à penetração e umidade do solo em diferentes ambientes no Pantanal Sul MatoGrossense (FN: mata semidecídua; CE1 e CE2: Cerradão; PC27, PC26, PC11: respectivamente, pastagem cultivada com 27, 26 e 11 anos de formação; PNpc, PNv3, PNv19: respectivamente, pastagem nativa sob pastejo contínuo e sem pastejo por 3 e 19 anos; * $\mathrm{e}$ ** : indicação de significância a 5 e $1 \%$, nas respectivas profundidades, nos contrastes FN vs PC27, CE1 vs PC26, CE2 vs PC11, PNv3 vs PNpc e PNv19 vs PNpc).

\section{CONCLUSÕES}

1. As pastagens promoveram perda da qualidade química do solo, notadamente na camada de $0-10 \mathrm{~cm}$, evidenciada pela redução nos teores de MOS e de cátions trocáveis $\left(\mathrm{Ca}^{2+}, \mathrm{Mg}^{2+}\right.$ e $\left.\mathrm{K}^{+}\right)$, soma de bases trocáveis, CTC a pH 7,0 e CTC efetiva, na pastagem cultivada, implantada em substituição à vegetação arbórea nativa, bem como pela redução na CTC a $\mathrm{pH}$ 7,0 e teor de MOS na pastagem nativa submetida ao sistema de pastejo contínuo.

2. A conversão da vegetação arbórea nativa em pastagem cultivada promoveu maior redução da qualidade química do solo na substituição à vegetação nativa caracterizada por árvores de menor porte e com menor fertilidade natural, independentemente do tempo de remoção da vegetação nativa.

3. A conversão da vegetação arbórea nativa em pastagem cultivada e o sistema de pastejo contínuo da pastagem nativa promoveram leve degradação da qualidade física do solo, evidenciada pelo aumento da densidade do solo e resistência do solo à penetração e diminuição da porosidade total, macroporosidade e condutividade hidráulica saturada, porém sem atingir limites considerados restritivos ao desenvolvimento do sistema radicular.

\section{LITERATURA CITADA}

ALVAREZ V., V.H.; NOVAIS, R.F.; BARROS, N.F.; CANTARUTTI, R.B. \& LOPES, A.S. Interpretação dos resultados das análises de solos. In: RIBEIRO, A.C.; GUIMARAES, P.T.G. \& ALVAREZ V., V.H., eds. Recomendações para o uso de corretivos e fertilizantes em Minas Gerais: $5^{a}$ Aproximação. Viçosa, MG, Comissão de Fertilidade do Solo do Estado de Minas Gerais, 1999. p.25-32.

ARATANI, R.G.; FREDDI, O.S.; CENTURION, J.F. \& ANDRIOLI, I. Qualidade física de um Latossolo Vermelho acriférrico sob diferentes sistemas de uso e manejo. R. Bras. Ci. Solo, 33:677-687, 2009.

ARAÚJO, R.; GOEDERT, W.J. \& LACERDA, M.P.C. Qualidade de um solo sob diferentes usos e sob cerrado nativo. R. Bras. Ci. Solo, 31:1099-1108, 2007.

ARSHAD, M.A.; LOWERY, B. \& GROSSMAN, R. Physical test for monitoring soil quality. In: DORAN, J.W. \& JONES, A.J., eds. Methods for assessing soil quality. Madison, Soil Science Society of America, 1996. p.123-141.

ASSIS, R.L. \& LANCAS, K.P. Avaliação dos atributos físicos de um Nitossolo Vermelho distroférrico sob sistema plantio direto, preparo convencional e mata nativa. R. Bras. Ci. Solo, 29:515-522, 2005. 
BAYER, C. \& MIELNICZUK, J. Dinâmica e função da matéria orgânica. In: SANTOS, G.A.; SILVA, L.S.; CANELLAS, L.P. \& CAMARGO, F.A.O., eds. Fundamentos da matéria orgânica do solo: Ecossistemas tropicais e subtropicais. 2.ed. Porto Alegre, Metrópole, 2008. p.7-18.

BENGHOUGH, A.G. \& MULLINS, C.E. Mechanical impedance to root growth: A review of experimental techniques and root growth responses. J. Soil Sci., 41:341-358, 1990.

BERTOL, I.; ALMEIDA, J.A.; ALMEIDA, E.X. \& KURTZ, C. Propriedades físicas do solo relacionadas a diferentes níveis de oferta de forragem de capim-elefante-anão CV. Mott. Pesq. Agropec. Bras., 35:1047-1054, 2000.

BLAKE, G.R. \& HARTGE, K.H. Bulk density. In: KLUTE, A., ed. Methods of soil analysis. 2.ed. Madison, American Society of Agronomy, 1986. p.363-375.

CANELLAS, L.P.; VELLOSO, A.C.X.; MARCIANO, C.R.; RAMALHO, J.F.G.P.; RUMJANEK, V.M.; REZENDE, C.E. \& SANTOS, G.A. Propriedades químicas de um Cambissolo cultivado com cana-de-açúcar, com preservação do palhiço e adição de vinhaça por longo tempo. R. Bras. Ci. Solo, 27:935-944, 2003.

CARDOSO, E.L.; SILVA, M.L.N.; MOREIRA, F.M.S. \& CURI, N. Atributos biológicos indicadores da qualidade do solo em pastagem cultivada e nativa no Pantanal. Pesq. Agropec. Bras., 44:631-637, 2009.

CARNEIRO, M.A.C.; SOUZA, E.D.; REIS, E.F.; PEREIRA, H.S \& AZEVEDO, W.R. Atributos físicos, químicos e biológicos de solo de cerrado sob diferentes sistemas de uso e manejo. R. Bras. Ci. Solo, 33:147-157, 2009.

COSTA, O.V.; CANTARUTTI, R.B.; FONTES, L.E.F.; COSTA, L.M.; NACIF, P.G.S. \& FARIAS, J.C. Estoque de carbono do solo sob pastagem em área de Tabuleiro Costeiro no sul da Bahia. R. Bras. Ci. Solo, 33:1137-1145, 2009.

EMPRESA BRASILEIRA DE PESQUISA AGROPECUÁRIA . EMBRAPA. Centro Nacional de Pesquisa de Solos. Sistema brasileiro de classificação de solos. 2.ed. Brasília, 2006. 306p.

EMPRESA BRASILEIRA DE PESQUISA AGROPECUÁRIA EMBRAPA. Centro Nacional de Pesquisa de Solos. Manual de métodos de análise de solo. 2.ed. Rio de Janeiro, 1997. $212 \mathrm{p}$

FERNANDES, A.F.; CERRI, C.C. \& FERNANDES, A.H.B.M Alterações na matéria orgânica de um Podzol Hidromórfico pelo uso com pastagens cultivadas no Pantanal Mato-Grossense. Pesq. Agropec. Bras., 34:19431951,1999

FERREIRA, D.F. Análises estatísticas por meio do SISVAR (Sistema par análise de variância) para Windows versão 4.0. In: REUNIÃO ANUAL DA REGIÃO DA BRASILEIRA DA SOCIEDADE INTERNACIONAL DE BIOMETRIA, 45., São Carlos, 2000. Anais... São Carlos, Universidade Federal de São Carlos, 2000. p.255-258.

FIDALSKI, J.; TORMENA, C.A.; CECATO, U.; BARBERO, L.M.; LUGÃO, S.M.B. \& COSTA, M.A.T. Qualidade física do solo em pastagem adubada e sob pastejo contínuo. Pesq. Agropec. Bras., 43:1583-1590, 2008.
GAMA-RODRIGUES, E.F.; GAMA-RODRIGUES, A.C.; PAULINO, G.M. \& FRANCO, A.A. Atributos químicos e microbianos de solos sob diferentes coberturas vegetais no norte do estado do Rio de Janeiro. R. Bras. Ci. Solo, 32:1521-1530, 2008.

HAMZA, M.A. \& ANDERSON, W.K. Soil compaction in cropping systems: A review of the nature, causes and possible solutions. Soil Till. Res., 82:121-145, 2005.

LANZANOVA, M.E.; NICOLOSO, R.S.; LOVATO, T., ELTZ, F.L.F.; AMADO, T.J.C. \& REINERT, D.J. Atributos físicos do solo em sistema de integração lavoura-pecuária sob plantio direto. R. Bras. Ci. Solo, 32:1805-1816, 2008.

LEMOS, R.C. \& SANTOS, R.D. Manual de descrição e coleta de solo no campo. 3. ed. Campinas, Sociedade Brasileira de Ciência do Solo, 1996. 84p.

MEURER, E.J., ed. Fundamentos de química do solo. 3.ed. Porto Alegre, Evangraf, 2006. 285p.

MOREIRA, A. \& MALAVOLTA, E. Dinâmica da matéria orgânica e da biomassa microbiana em solo submetido a diferentes sistemas de manejo na Amazônia Ocidental. Pesq. Agropec. Bras., 39:1103-1110, 2004.

OLIVEIRA, J.T.; MOREAU, A.M.S.S.; PAIVA, A.Q.; MENEZES, A.A. \& COSTA, O.V. Características físicas e carbono orgânico de solos sob diferentes tipos de uso da terra. R. Bras. Ci. Solo, 32:2821-2829, 2008.

OLIVEIRA, T.S.; COSTA, L.M.; FIGUEIREDO, M.S. \& REGAZZI, A.J. Efeitos de ciclos de umedecimento e secagem sobre a estabilidade de agregados em água de quatro Latossolos brasileiros. R. Bras. Ci. Solo, 20:509515, 1996.

PORTUGAL, A.F.; COSTA, O.D.A.; COSTA, L.M. \& SANTOS, B.C.M. Atributos químicos e físicos de um Cambissolo Háplico Tb distrófico sob diferentes usos na Zona da Mata mineira. R. Bras. Ci. Solo, 32:249-258, 2008.

RANGEL, O.J.P. \& SILVA, C.A. Estoques de carbono e nitrogênio e frações orgânicas de Latossolo submetido a diferentes sistemas de uso e manejo. R. Bras. Ci. Solo, 31:1609-1623, 2007.

SALIS, S.M. Distribuição de espécies arbóreas e estimativa da biomassa aérea de savanas florestadas, Pantanal da Nhecolândia, estado do Mato Grosso do Sul. Rio Claro, Universidade Estadual Paulista, 2004. 63p. (Tese de Doutorado)

SANTOS, R.D.; CARVALHO FILHO, A.; NAIME, U.J. \& OLIVEIRA, H. Pedologia. In: BRASIL. Ministério do Meio Ambiente, dos Recursos Hídricos e da Amazônia Legal. Plano de Conservação da Bacia do Alto Paraguai (Pantanal) - PCBAP.Diagnóstico dos meios físicos e bióticos: Meio físico. Brasília, 1997. v.2. p.121-293.

SANTOS, S.A.; COSTA, C.; SOUZA, G.S.; POTT, A.; ALVAREZ, J.M. \& MACHADO, S.R. Composição botânica da dieta de bovinos em pastagem nativa na sub-região da Nhecolândia, Pantanal. R. Bras. Zootec., 31:1648-1662, 2002 . 
SILVA JÚNIOR, M.L.; DESJARDINS, T.; SARRAZIN, M.; MELO, V.S.; MARTINS, P.F.; SANTOS, E.R. \& CARVALHO, C.J.R. Carbon content in Amazonian Oxisols after Forest conversion to pasture. R. Bras. Ci. Solo, 33:1603-1611, 2009.

SILVA, M.B.; KLIEMANN, H.J.; SILVEIRA, P.M. \& LANNA, A.C. Atributos biológicos do solo sob influência da cobertura vegetal e do sistema de manejo. Pesq. Agropec. Bras., 42:1755-1761, 2007.
STOLF, R. Teoria e teste experimental de fórmulas de transformação dos dados de penetrômetro de impacto em resistência à penetração. R. Bras. Ci. Solo, 15:229235, 1991.

TAYLOR, S.A. \& ASHCROFT, G.L. Physical edaphology: The physics of irrigated and nonirrigated soils. San Francisco, W. H. Freeman, 1972. 532p. 